\title{
Community Participation and Health Promotion for Senior Citizens
}

\author{
MinGyu Choi \\ Graduate School of Education \\ Tohoku University \\ Sendai, Japan \\ m.gyu@gmail.com
}

\begin{abstract}
The purpose of this study was to reveal, through qualitative research, how the physical, mental and social awareness and behavior of a long-term care prevention activity group of senior Japanese citizens has changed, and to investigate what kind of relationship these qualities have. These two objectives were to be achieved by analyzing the aforementioned group's participation in activities from the start of their participation to present. As an example of this process, the Tsurugaya Refresh Club, found in the Tsurugaya district of Sendai City, was selected. This was due to said district having the highest percentage of senior citizens in Sendai City at $38.5 \%$, and due to the Club independently conducting long-term care prevention activities. As a result, consciousness about one's physical and mental health changed by improving human relations (social health) leading to a change in behavior towards long-term care prevention activities in everyday life. From these results, it could be seen that one's social health provides support for one's physical and mental health. In addition, by continuing with participation in such activities, participants developed an interest in the local area, in turn leading to further participation in other social situations, thus resulting in a cyclical effect of improving human relations. It is in cyclical processes such as these that we find an abundance of social capital. Additionally, regarding the management of independent groups involved in long-term care prevention activities, it was found that participants felt a great burden when first experiencing a management role. However, it was also found that this burden could be reduced by conducting learning activities about health and by sharing information about health among managers. Consequently, management processes such as these play a role for the managers themselves in changing their own awareness and behavior regarding their health. As mentioned above, activities conducted through participation in independent longterm care prevention activity groups also perform a role in the realization of health promotion.
\end{abstract}

Keywords- Health promotion, Community participation. Senior citizens. Long-term care prevention activity

\section{RECOGNIZING THE PROBLEM}

In Japan has the highest percentage of senior citizens in the world (World Bank, 2015). Additionally, Cabinet Office, Government of Japan (2011) has anticipated that the percentage of senior citizens will continue to increase until the $2060 \mathrm{~s}$, when it predicts that one in every 2.5 people will be aged over 65 .
Although each area of Japan has conducted various social activities in their respective local communities, there are several examples of the scale of these activities shrinking, or ceasing to exist entirely due to the aging society phenomenon. Due to this, unlike in the past, there are instances where senior citizens are working as the leaders of their local community's activities. In accordance with the aging phenomenon of local communities, senior citizens' roles have changed from a type of recipient, one who benefits from the service provided, to the provider of said service or activities. Thus, local communities in Japan have changed due to the aforementioned phenomenon.

In this modern day local community, which is rapidly changing due to the aging phenomenon, the questions of how seniors can continue to live healthily in their local community, and what is maintaining their health are raised. Regarding these questions, it has already been made clear that senior citizen participation in the community is effective in helping said senior citizens live healthily in their local community (Yoshinori Fujiwara et al., 2005),(Egawa Midori, 2013), (Kurabayashi Shinobu et al., 2002).

However, the question still remains as to which kind of social activities help to maintain the health and participation of senior citizens. There are different kinds of social activities aimed at senior citizens, mainly split into two categories: those run by local governments or specialist staff, and those which are independently organized by the senior citizens themselves.

Due to the fact that social activities run by local governments and specialist staff have a guaranteed level of expertise and finance compared to those organized by independent groups, there is a tendency to believe that said activities are better for maintaining or improving the health of senior citizens. However, even though these activities do indeed come with the aforementioned level of expertise and financial security, they are often held in the form of short-term programs, and because of this we can say that organizations run independently by residents are better for the health of senior citizens (Osaka Nobuko et al, 2009), (Horikawa Shunichi, 2015).

Thus, looking at matters from a health improvement perspective, there does not appear to be a great difference between groups run by local governments and with instruction from specialist staff and those run by independent groups of senior citizens. Additionally, it is also thought that in the process of conducting activities, independent groups in fact 
provide greater social capital than those run by local governments and specialist staff.

Regarding the participation of senior citizens in activities run by independent groups over the last 25 years, Kobayashi Erika (2015) states that 'the upper social activity participation bracket is expanding, whereas the non-participation bracket is shown to be shrinking.' In line with this, independent activity groups for senior citizens guarantee sustainable healthy activities for senior citizens and also perform the role of helping to improve their health.

To proceed further with this argument, we must first define what health is. There exist several definitions for the word 'health,' however, for the purpose of this research I will use the definition provided by WHO.

WHO (1946) defines health as "a state of complete physical, mental and social well-being and not merely the absence of disease or infirmity," with health promotion defined as "the process of enabling people to improve and gain greater control over their health" in Ottawa (WHO, 1986). This form of health promotion is gaining attention as being possible to realize through methods such as adult education and health education (UNESCO, 1999).

Be that as it may, the vast majority of the field of health promotion stresses the importance of the alteration of behavior (Japanese Society of Health Education and Health Promotion, 2003). however, consciousness when thinking about the health of senior citizens and educational problems, we must also consider the alteration of consciousness. . In the specific adult education field of empowerment, emphasis is placed on the alteration of behavior, but in this field, emphasis is placed on the alteration of consciousness at an earlier stage.

In line with this, in this paper I will consider the process of change in consciousness and behavior of senior citizens that arises through their participation in society. In addition, from this point of view, I will also examine in detail how the consciousness of senior citizens changes regarding physical, mental and social health and in turn how this affects their behavior. In this paper I will also consider how the social capital of senior citizens increases during the aforementioned process of change.

\section{RESEARCH TOPICS AND METHODS}

Based on the above, the main question of this research is 'how have the physical, mental and social awareness and behavior of an independent group Japanese senior citizens changed since they began participating in social activities, and what kind of interrelationship do these qualities have?' and to investigate and answer this through qualitative survey methods. The reason for this research method is because the majority of research into the social participation of senior citizens and their health is conducted through qualitative surveys. For example, in the research of Horikawa (2015), through a quantitative survey aimed at senior citizens participating in care prevention activities organized by independent groups, it was found that participation in said activities have positive effects on the physical, mental and social health of senior citizens. It has already been found that participation in independent groups such as these improves one's physical, mental and social health, but investigating the interrelationship between these three aspects is thought to be the next issue at hand. However, there is a limit to how far we can investigate the aforementioned interrelationship and how one's awareness and behaviour with regard to health has changed through quantitative research.

As an example, in this paper I will use the independent activity group for long-term care prevention for senior citizens, Tsurugaya Refresh Club. The reason for selecting this group lies in when it was established. The Tsurugaya Refresh Club is an independent group that was established in 2005 by senior citizens and conducts long-term care prevention activities. In Japan, in fiscal year 2006, a year after the establishment of the Tsurugaya Refresh Club, changes were made to the system for care insurance and as such, local support projects were set up in order to prevent the need for long-term care in municipalities all over the country, and have been implemented since then (Ministry of Health, Labour and Welfare, 2009). Thus Tsurugaya Refresh Club, now in its 11th year, was slightly ahead of the industry and is the group I have chosen to focus on in this paper.

\section{OUTLINE OF THE SURVEY}

Tsurugaya Refresh Club, the subject of my survey and hereafter referred to as 'the independent activities group,' is based in the Tsurugaya area where the percentage of senior citizens stands at $38.5 \%$. This figure sees the area as second in the prefecture and first in Sendai (as of October 2015).

In the Tsurugaya area, taking advantage of the 'Tsurugaya Local Care Project for Senior Citizens to Prevent Long-term Care' which was held in fiscal year 2004 at the local health and welfare center, local residents began recruiting facilitators for a care prevention activity group. Following the sixth meeting of the aforementioned project, the Tsurugaya Refresh Club was formed in January 2005. Thus meaning the Tsurugaya Refresh Club was founded as an independent group for the long-term care prevention for senior citizens that is run by local senior citizens who had taken training the previous year, and is also independently participated in by local senior citizens. They host their activities at five different locations in the Tsurugaya area. As each location has its own different activity days, it allows participants to freely participate at times that suit them in a familiar environment. The survey conducted as part of the research for this paper was mainly done so at the Mutsumi Meeting Center, where the president of the Tsurugaya Refresh Club conducts his activities.

Activities usually include facilitators giving everyday information and information regarding health to participants, stretching, general recreation, and locomotive syndrome gymnastics. In addition to this, there is also a free talk time before activities are concluded.

Membership is 600 yen for three months, and this cost is used on fees to rent the facilities used, the fees incurred when making information leaflets, insurance for participants and other maintenance costs. 
The survey was conducted in stages, with the pre-survey conducted in August 2015 with Mr. A, the president of the independent activities group and facilitator Ms. B. Between September and November 2015, the survey was conducted further with other facilitators and members. The survey was conducted on the independent activities group activity days twice a month on the second and fourth Wednesday of the month while visiting the facility being used. The survey mainly consisted of an interview with participants regarding changes in their health and daily lives since participating. In total there were seven persons who cooperated with this survey.

TABLE I. OUTLINE OF SURVEY PARTICIPANT MEMBERS.

\begin{tabular}{|c|c|c|c|c|}
\hline & Age & Gender & $\begin{array}{c}\text { Living } \\
\text { With }\end{array}$ & $\begin{array}{c}\text { Participation } \\
\text { Status }\end{array}$ \\
\hline A & 74 & Male & Wife & President \\
\hline B & 75 & Female & Husband & Facilitator \\
\hline C & 85 & Female & N/A & Member \\
\hline D & 72 & Male & Wife & Facilitator \\
\hline E & 71 & Female & Husband & Facilitator \\
\hline F & 71 & Female & N/A & Facilitator \\
\hline G & 78 & Female & Son & Member \\
\hline
\end{tabular}

IV. THE EXPANSION OF SOCIAL ACTIVITIES, AND THE

PROCESS OF CHANGE IN THE AWARENESS AND ACTIONS REGARDING ONE'S HEALTH AND THE INTERRELATIONSHIP BETWEEN THEM

Figure 1, pictured below, is a figure of the analysis of the survey conducted. Examining the figure, rectangular boxes outlined with thin lines represent 'awareness and change in actions regarding physical and mental health,' and rectangular boxes with dotted lines represent 'awareness and change in actions regarding social health.' Rectangular boxes with thick lines focus on those with managing roles in the independent activities group, and represent 'awareness and the process of change in actions since performing their managing role.'

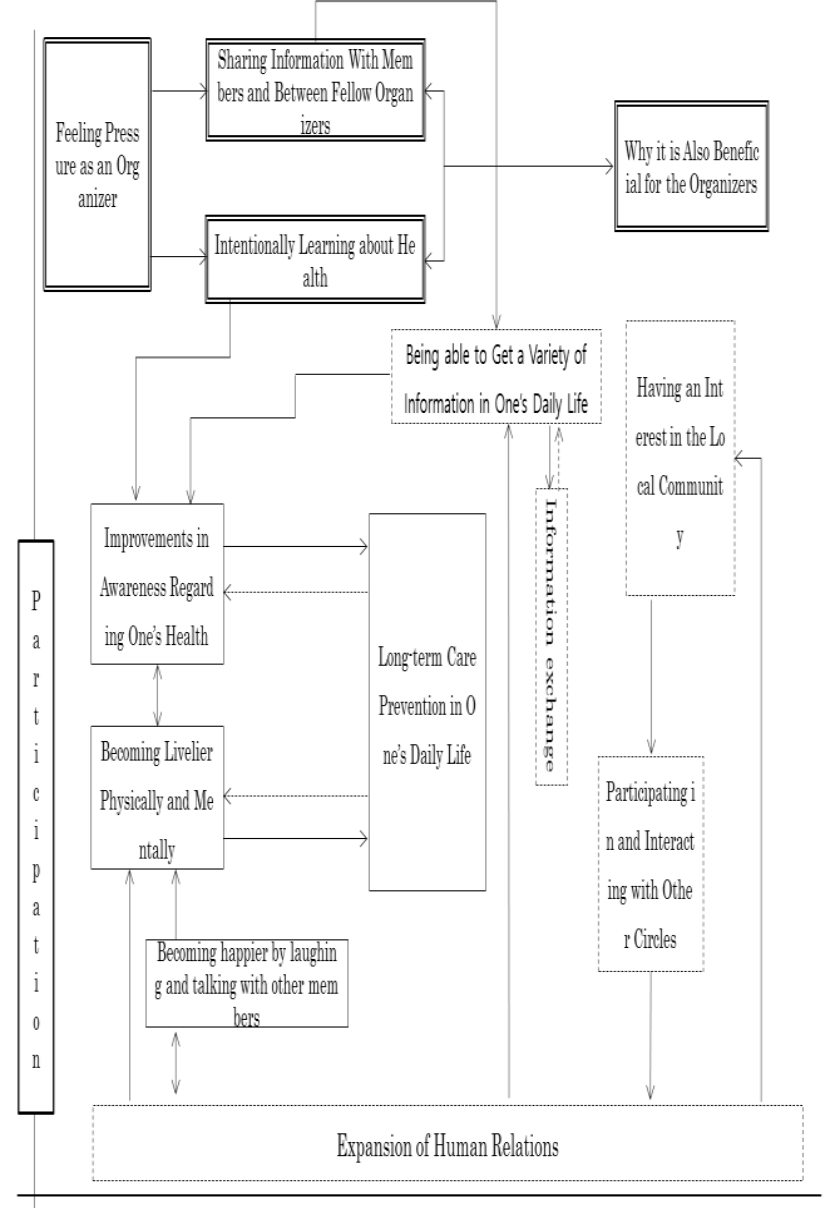

Fig. 1. Senior citizen participation in 'independent groups for long-term care prevention,' and the process of change in the awareness and actions regarding one's health and the interrelationship between them

In the explanation of the analysis written below, in order to distinguish between each category, items relating to 'awareness and change in actions regarding physical and mental health' are highlighted by the ' $<>$ ' symbols, with items relating to 'awareness and change in actions regarding social health' highlighted by '[ ]' symbols.

From analyzing the interview, we can see that social health activities support physical and mental health activities. In other words, after participating in the independent activities group, one's human relations are expanded, which in turn supports one's physical and mental health activities. By expanding one's human relations, we can say that one can obtain a greater amount of information in one's daily life.

\section{A. Expansion of Human Relations}

Q : Did you get to know more people by participating in these activities? For example, greeting people when you go out.

D : Yes, I've found I can communicate with more people now. I've found there are more I can talk to. 
B. Being able to Get a Variety of Information in One's Daily Life

C : Yes, we get a lot of information. Things like "that hospital is good, or not so good." We also get information on things that are good for our health. If we were by ourselves, we wouldn't get this kind of information.

By expanding one's human relations, it's true that one can obtain more information in one's daily life, but by realizing this process, awareness regarding one's health also improves.

\section{Improvements in Awareness Regarding One's Health}

E : As we get lots of information, I try my best to stick to what we're told, be that in terms of food, generally being careful or just taking things on board. When I go food shopping, unfortunately, there are some things which I buy that are good for me, but I don't really like. [...] I read books and think about what kind of ingredients are good for my health. It's because of this I'm making food that I've never made before and even using ingredients I've never used before too.

A : Since I joined this group, I've started thinking about and even doing exercise in my own way.

In addition, by expanding one's human relations, one can also become livelier both physically and mentally.

\section{Becoming Livelier Physically and Mentally}

E : I didn't used to have a particular interest in health or the specifics of it. Being young also helped, but I've always enjoyed exercise. Exercising here, however, has taught me that certain muscles have certain jobs and uses, so it makes you want to tone your body. Before joining this group I didn't exercise much, but after joining and exercising here I feel better in myself.

E : I don't really laugh and joke too much at home, so coming here and laughing and talking with everyone has made me happier as well.

C : It's fun listening to what people have to say and joining in exercising with everyone here.

From these comments we can see that the relationship between social health activities and physical and mental health activities in the independent activities group is one where the social aspect supports the physical and mental aspects. With this kind of relationship between the aspects, senior citizens continue to participate in activities organized by independent groups for long-term care prevention, but it is lengthier, deeper participation that sees further long-term care prevention benefits in one's daily life. Through social health activities, a change in awareness occurs, and by furthering this participation a change in action also occurs by conducting long-term care prevention in one's daily life.

\section{E. Long-term Care Prevention in One's Daily Life}

A : I used to just sit at home watching tv and reading the newspaper, but since coming here I've started to exercise at home too, and not just sit around.

F : When I go shopping I've started to walk to the shops.

Q : How about before you joined here?

F : I always used to go by car, even though it was a walkable distance.

E : Now, even by myself, when I feel that my back aches I know it might be down to a lack of abdominal exercise, so I've started doing a little exercise myself while lying down.

Participating in the independent activities group has done more than just spreading social health activities internally, it has also spread this outside the group. Specifically, this process of expanding social activities externally occurs by members developing an interest in the local community after expanding their human relations internally, within the group. By furthering their participation, they tend to seek participation in, and interaction with, other circles. This sees a cyclic effect of an expansion of human relations take place, and the process itself leads to an abundance in social-related capital.

\section{F. Having an Interest in the Local Community}

Q : Have you noticed any changes in yourself?

F : I feel I've become more active in the local area. Thanks to this group I've come to know everyone here, so I've started greeting them and feel my personal circle has expanded. I don't really have much of a chance to talk to people who live 20 houses away, but here you can talk to people for a while and it has allowed me to build relationships with them.

\section{G. Participating in and Interacting with Other Circles}

E : I love exercise, so I've also started to participate in ground golf and interacting with other circles of people. I'm the kind of person who won't go outdoors without a reason because I get comfortable relaxing at home. I have a tendancy like that to stay at home and I was only really concerned about my immediate surroundings and personal life.

\section{H. Social Health Activities}

Q : What have you learned from the activities so far, do you find your way of thinking has changed?

E : I used to just keep quiet and walk by people before, but now I try to greet people even if I don't know them.

Next, examining the meaning that running the long-term care prevention activities of an independent group has, when organizers first began participating, they remarked that they felt pressure or a burden. However, this sense of pressure can be 
reduced by learning about health and by sharing information about health between the members and fellow organizers. Moreover, this process involved in organizing can be said to be beneficial for the organizers themselves too.

\section{Feeling Pressure as an Organizer}

$\mathrm{Q} \quad$ : Do you feel pressure as a facilitator?

F : A lot. I want to conduct activities that are a little different, so I really think hard the day before. Once you get used to it, you sometimes just use ideas you come across online or in books so that the content is generally set. Then it's just a matter of making minor adjustments. In the last half a year it's been quite relaxed, but even then you do feel some level of stress the day beforehand.

\section{J. Intentionally Learning about Health}

D : Since joining the activities, I've been watching the news and reading books, and I've become interested in following up topics by reading related articles and other information.

Q : Do you mean that by participating in these activities, it has made you more interested in that kind of information?

D : Yes, that's right.

\section{K. Sharing Information With Members and Between Fellow Organizers}

D : You have to know about what you're teaching people. I've become more interested in things by reading the newspaper and reading books. I try and talk about activities that really invigorate the brain and have members do so too, so you can see where the want to follow with added knowledge comes from.

Q : And you do this while providing members with related information?

D : Yes, we share the information with everyone.

\section{Why it is Also Beneficial for the Organizers}

Q : Thinking back, did you have the chance to speak in front of people before participating here?

E : Not really, no.

Q : Are you glad you can communicate well in front of everyone now?

E : It's something I didn't think I'd be able to do because I'd always worked in an office until I was in my 50s. Then it got to a point where I got tired of it and I wanted to get out there and work, so I changed jobs to working in a factory. There I just felt I had to work well each individual day. Office work just keeps going on. Even after you go home, you have numbers floating around in your head. I don't think I ever really spoke in front of people.
D : In the end, I think it helps others, but not only that, it also helps you too.

Q : Do you mean in a physical sense, or in terms of enjoyment, or all-round?

D : As I just mentioned, doing these kinds of activities makes you more interested in the news and other information. You learn a lot yourself by remembering things and teaching others. You gain more knowledge and teach others about it, but were it not for these activities you wouldn't be interested in that news or particular TV programme. You purposely watch out for exercise and nutrition programmes etc. and think about which information to introduce to everyone. So in the end, it's not just for others, it's good for yourself too.

\section{DisCUSSION AND CONCLUSION}

This study investigated the kind of interrelationship between physical, mental and social health and how people's awareness and actions regarding them changed. From the research and surveys conducted, it was highlighted that social health supports physical and mental health and that depending on this one's awareness of health and actions regarding it would change. In addition, this interrelationship was also one of the reasons for participation in activities.

Moreover, senior citizens experienced a change in their awareness of their own health through participation in independent groups for long-term care prevention. Research showed that with their new awareness they have more control over their health and begin the process of improving it through their own chosen actions. In line with this, we can say that participation in the activities of independent groups for the long-term care prevention of senior citizens helps to perform the role of realizing health promotion.

Until now, there has been little research attempting to analyse the process of change regarding health and the relationships concerning it from the perspective of mutual learning. That is to say that research up until this point has mainly focused solely on changes in behaviour. However, my research has, from the perspective of mutual learning, included the areas of change in awareness and social capital. In addition, one can say that revealing the process of change relating to health by using concrete examples has given this further meaning.

As can be seen in the examples highlighted, in order for senior citizens to live healthily in their local society, a place where they can independently participate in local social activities is necessary. What was found to be key was not that instruction is provided by the local government or specialist staff, but simply support.

The main example given in this paper was that of longterm care prevention activities run by independent groups for senior citizens. In future, however, I would like to focus further on the independent groups of senior citizens and their newlydeveloped personalities and analyze the process of change in their awareness and actions regarding health in further detail. 


\section{REFERENCES}

[1] Cabinet office, Government of Japan, The Aging Society: Current Situation and Implementation Measures, Cabinet office, Government of Japan, 2011.

[2] Egawa Midori, "Social participation and well-being of elderly adults in Japan," Journal of The Japan Association of Regional Development and Vitalization, Vol. 4, pp.67-74, 2013.

[3] HORIKAWA Shunichi, "Community based activity which prevent the elderly from developing preventable physical disabilities: from the experience of Iki-iki Hyaku-sai Taiso," Sogo rehabilitation, Vol. 43(9), pp.825-829, 2015.

[4] Japanese Society of Health Education and Health Promotion, KenKou KyouIku - health promotion no TenKai (Health Education - Expansion of health promotion), HOKENDOHJINSHA Inc, 2003.

[5] Japanese Society of Health Education and Health Promotion, KenKou KyouIku - health promotion no TenKai (Health Education - Expansion of health promotion), HOKENDOHJINSHA Inc, 2003.

[6] Kurabayashi Shinobu, Gokan Yoko, Haruyama Sanae, Osawa Manami, Aoki Tomoko, and Fujioka Yumi, "The study of the factors related to social participation by aged people in a depopulated area," The annual reports of Gunma Prefectural College of Health Sciences, Vol. 9, pp. 009-116, 2002.

[7] Osaka Nobuko et al., "TaiTouShi Ni Okeru Kaigo Yobou Zigyou No Tori Kumi: -Senn Monn Syoku SyuTai No KyouShiTu To ZyuMin SyuTai No Katudou No Kaigo Yobou KouKa No HiKaku- (Effort of Long-term prevention business in City of TaiTou : - Comparison with professional and civil subject in Long-term prevention activities)," Congress of the Japanese Physical Therapy Association, Vol. 2008(0), E3P1185-E3P1185, 2009.

[8] Ministry of Health, Labour and Welfare, A manual of Long-term prevention, Ministry of Health, Labour and Welfare, 2009.

[9] UNESCO, 6b Health promotion and health education for adults, Druckerei Seemann, Hamburg, 1999.

[10] World Bank, Population ages 65 and above (\% of total), Overview per country, World Bank, 2015.

[11] WHO (World Health Organization), CONSTITUTION OF THE WORLD HEALTH ORGANIZATION, WHO, 1946.

[12] ----------------------, Ottawa Charter for Health Promotion, WHO, 1986

[13] -------------------, Ottawa Charter for Health Promotion, WHO, 1986 